OPEN ACCESS

Edited by:

Veronica A. Segarra,

High Point University, United States

Reviewed by: Kellyann Jones-Jamtgaard, Other, United States Kirsten Block, American Society for Biochemistry and Molecular Biology, United States

*Correspondence: Teresita Padilla-Benavides tpadillabena@wesleyan.edu

tThese authors have contributed equally to this work and share first authorship

Specialty section:

This article was submitted to STEM Education, a section of the journal

Frontiers in Education

Received: 24 August 2021 Accepted: 15 October 2021 Published: 03 November 2021

Citation:

Barnes L, Grajales J, Velasquez Baez J, Hidalgo D and Padilla-Benavides T (2021) Impact of Professional and Scientific Societies' Student Chapters on the Development of Underrepresented

Undergraduate Students.

Front. Educ. 6:763908. doi: 10.3389/feduc.2021.763908

\section{Impact of Professional and Scientific Societies' Student Chapters on the Development of Underrepresented Undergraduate Students}

\author{
Lily Barnes ${ }^{1 \dagger}$, Joshua Grajales ${ }^{1 \dagger}$, Jocelyn Velasquez Baez ${ }^{1 \dagger}$, Daniel Hidalgo ${ }^{2}$ and \\ Teresita Padilla-Benavides ${ }^{1 *}$
}

${ }^{1}$ Department of Molecular Biology and Biochemistry, Wesleyan University, Middletown, CT, United States, ${ }^{2}$ Department of Molecular, Cell and Cancer Biology, University of Massachusetts Medical School, Worcester, MA, United States

Undergraduate students from historically underrepresented groups (URG) in institutions of higher education with a focus on science, technology, engineering, and math (STEM) careers often lack the support, resources, and community necessary to succeed in their desired fields. Through mentoring, webinars, seminars, and various research presentation opportunities, national societies and "locally-based" institutional student chapters provide atmospheres in which URG undergraduates can develop the skills required for academic and professional careers in STEM. In addition, national societies and student chapters contribute to outreach activities aimed towards the public in order to foster interest in STEM, as well as to primary and secondary school students to help them develop competency in skills and areas that lead to successful STEM careers. While many of these societies have operated for decades, the onset of the COVID-19 pandemic proved to be an unexpected roadblock, creating difficulties in terms of maintaining community dynamics and overcoming limits on in-person meetings. Though the conditions were challenging, they allowed for new perspectives on problem-solving in the face of adversity. The pandemic promoted the development of creative ways by which institutions and national societies could continue to educate students virtually. In this review, we discuss the role of national societies and student chapters in providing URG students with resources and skills to succeed in STEM fields while incorporating them into a community of like-minded peers with similar experiences.

Keywords: STEM, professional societies, student chapters, underrepresented students, inclusion, diversity, academic success

\section{INTRODUCTION}

A variety of historical, economic, and social factors have contributed to the underrepresentation of certain social groups in science, technology, engineering, and math (STEM) fields of study (Branchaw et al., 2020). This lack of diversity is most prevalent at the college-level of education, and in consequence, extends to the graduate school level (Figure 1). As a result, pursuing careers contingent on college-level degrees becomes a hurdle for aspiring minority scholars, as these environments appear less welcoming and at times unavailable to them. In recent years, professional and scientific societies have had increased involvement in efforts to promote 
A
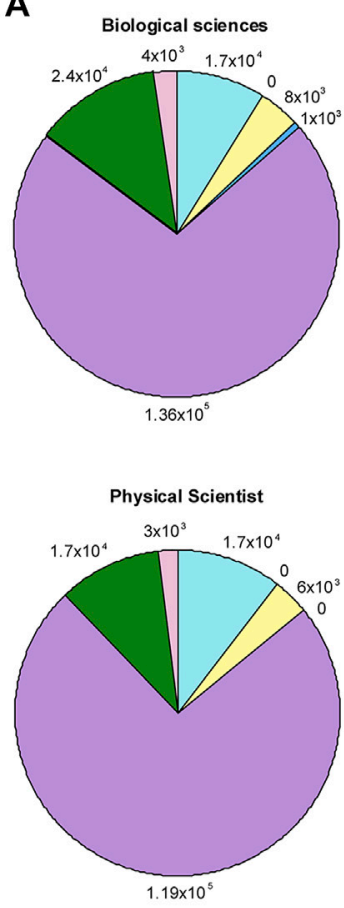
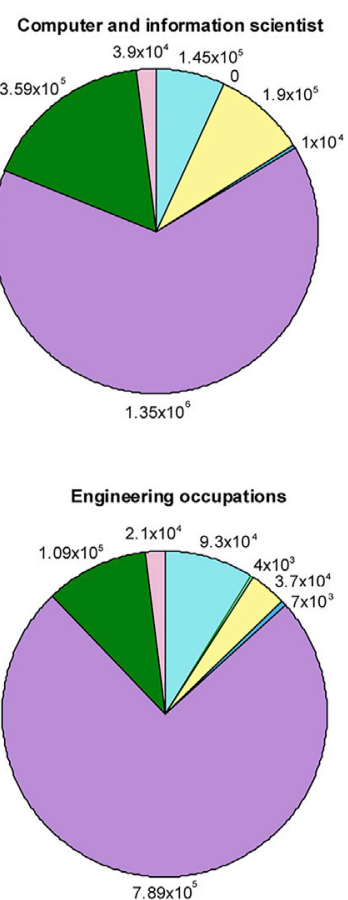
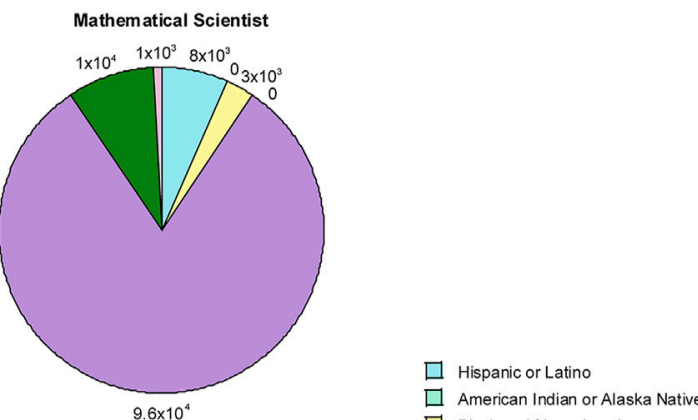

$\square$ Black or African American

$\square$ Native Hawaiian or Other Pacific Islander

$\square$ White

$\square$ Asian

More than one race

B

Percentage of individuals with a doctoral degree by ethnicity conducting research (2017)

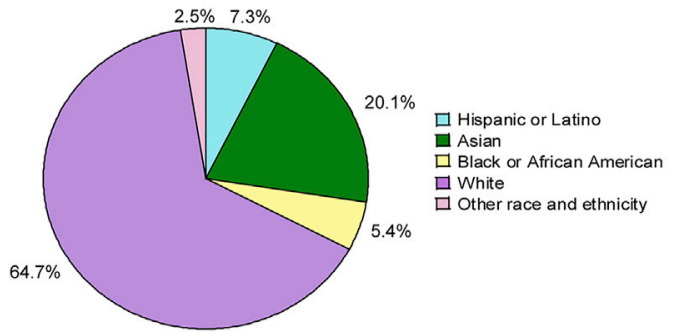

FIGURE 1 | Demographic distribution of professionals in the main STEM careers. (A). Employed scientists and engineers with a bachelor's degree occupation, ethnicity, and race (adapted from https://www.nsf.gov/statistics/2020/nsf20300/\#chp2 "Employed scientists and engineers, by highest degree level, occupation, ethnicity, and race: 2017 "). (B). Percentage of early career doctorates by ethnicity. Individuals who earned their first doctoral degree in the past 10 years and work at academic institutions and perform federally funded research and development centers (adapted from https://www.nsf.gov/statistics/srvyecd/\#tabs-s).

diversity, equity and inclusion (DEI) in academia. There is an identified need to increase retention of minorities in colleges both at the student and faculty levels, as well as to ensure the completion of academic degrees (Vernon and Morris, 2017; Womack et al., 2020). Thus, a number of national organizations have committed to continuously create innovative opportunities for underrepresented groups (URG) of students (Vernon and Morris, 2017), e.g., the Society for Advancing Chicanos/Hispanics and Native Americans in Science (SACNAS), the American Indian Science and Engineering Society (AISES), the American Society for Biochemistry and Molecular Biology (ASBMB), the Annual Biomedical Research Conference for Minority Students (ABRCMS) hosted by the American Society for Microbiology (ASM), the American Society for Cell Biology (ASCB), the Biophysical Society, and the Sigma Xi Society. These major organizations have a long-standing record of supporting URG at the professional and personal levels by fostering communities that provide mentorship and support. This mission is the same throughout each student initiative, which are established by a variety of institutions all over the United States and are promoted via community outreach. There are different mechanisms by which these societies strengthen their communities (Figure 2), and these strategies are designed for distinct audiences, ranging from specific STEM fields to DEI efforts, such as the establishment of student chapters.

In this review, we focus on the use of URG student chapters of professional societies as tools that allow students to become active members of scientific and professional organizations while also receiving mentoring and support. Student chapters are an important component of professional societies, and they allow students to connect with the community directly. As such, 


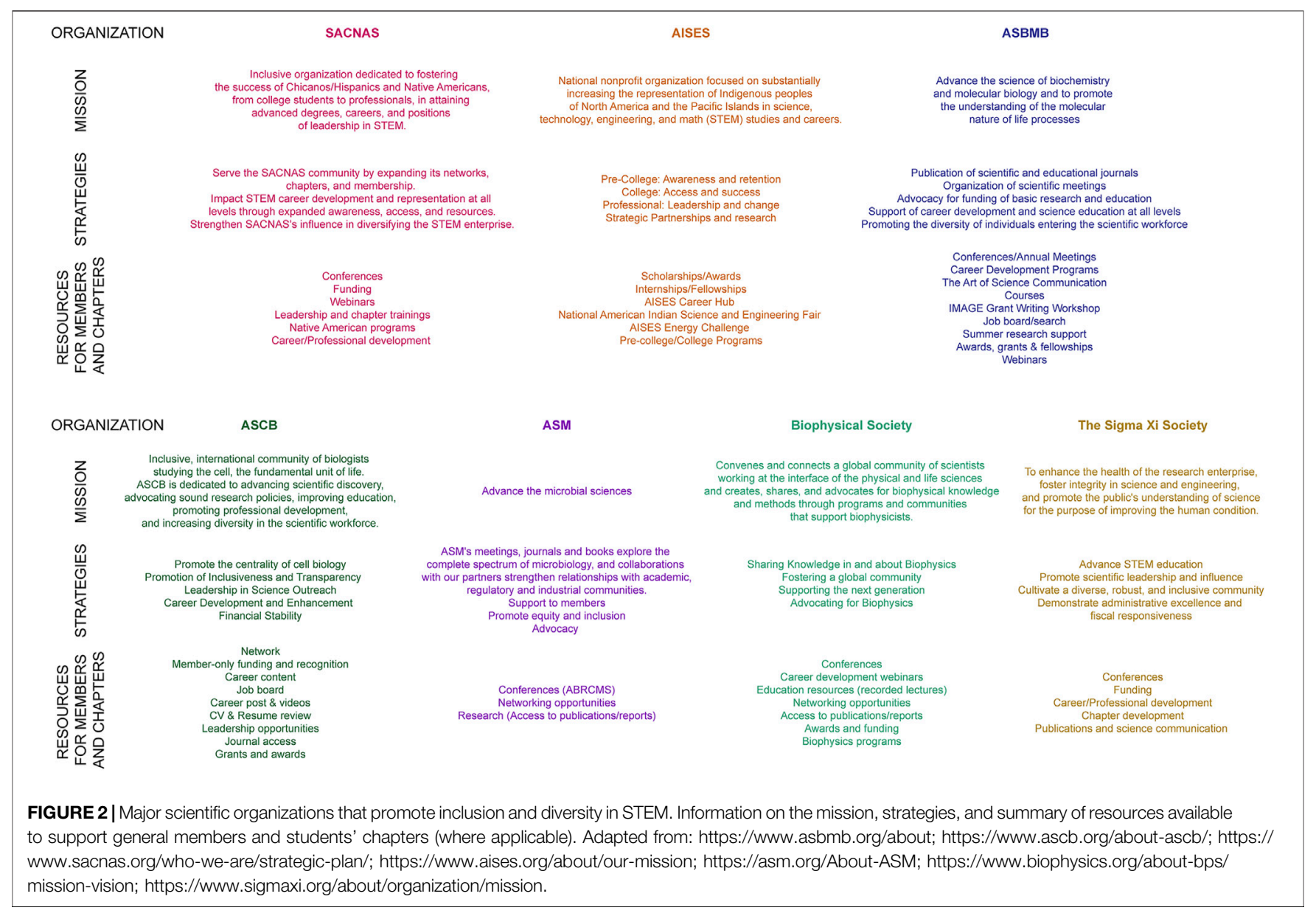

student chapters have become part of efforts directed to make a difference within less privileged social groups. Oftentimes, these chapters reflect that large entities, such as scientific societies, realize that there is a social problem and are committed to solving such problems by connecting with local communities. However, these are not the only ways by which such organizations support students. Within these chapters, students can feel that they are part of something greater, beyond just participating in STEM activities at their schools. Events organized by professional societies and associated student chapters not only open the door to the scientific world, but also provide great networking opportunities for students to learn about and experience different professions and areas of research. Student chapters of professional and scientific organizations provide a forum in which students can expand their networks with experts in scientific fields and participate in professional and scientific development programs which ultimately may help them secure their first jobs. Student chapters also provide opportunities to develop leadership skills, as the students are in charge of proposing, planning, and executing diverse activities for their community. Such organizations allow the students to give back to the communities that fostered their growth. By organizing scientific outreach events, the students can reach out to the public as educators, ultimately enabling the students to learn how to share their knowledge with individuals outside the scientific community. These contributions to society are essential to raising awareness of common scientific and health problems, and they highlight the importance of STEM careers in hopes of promoting the next generation of professionals.

Student chapters are especially important to students from URG because they contribute to their gradual integration into the areas in which they are scarcely represented. Prior to these efforts, the absence of fellow minorities in STEM fields was often taken as a sign of an unwelcoming environment. National organizations seek to dismantle this conception, thereby encouraging and supporting minorities in their pursuit of STEM educations and careers. At an institutional level, undergraduate students regard chapters as cohorts of like-minded students with similar goals educational and community goals. Chapters are composed of aspiring scholars who seek to not only improve their current generation's opportunities in professional STEM fields but also those of future generations. In addition to this, faculty advisors serve as inspiration, guidance, and support for undergraduates as they traverse college life. Advisors and mentors provide students with examples of the professional experiences that college students may expect to have 1 day. In summation, each student chapter offers a support system to students by 
TABLE 1 | Main awards offered to undergraduate students by the major scientific societies in the USA

\section{Organization}

\section{Fellowship or award}

description
Society for Advancement of Chicanos/Hispanics and Native Americans in Science

The American Indian Science and Engineering Society

American Society for Biochemistry and Molecular Biology

The American Society for Cell Biology

The Biophysical Society

Sigma XI
-Travel scholarship \$1,000

https://www.sacnas.org/what-we-do/conference/travel-scholarships/

-Yearly Scholarships

- Leadership Summit Registration Scholarships

-AISES 3M Scholarship

-AISES A.T. Anderson Scholarship

-AISES Aristocrat/NGT Scholarship

-AISES Burlington Northern Santa Fe (BNSF) Foundation Scholarship

-AISES Chevron Scholarship

-AISES Energy Scholarship, Mentorship and Workforce Development Cohort Program

-AISES ExxonMobil Scholarship

-AISES Intel Growing The Legacy Scholarship Program

-AISES National Conference Travel Scholarships

https://www.aises.org/students/scholarships

- Chapter awards

https://www.aises.org/students/college-chapter-awards

- General resources

https://www.asbmb.org/career-resources/awards-grants-fellowships

- Student research award \$1,000

https://www.asbmb.org/education/student-chapters/awards/undergraduate-research

-Tuition scholarship $\$ 2,000$

https://www.asbmb.org/diversity/undergraduate-scholarship

-Trip to DC-inform policy makers on the importance of research

https://www.asbmb.org/advocacy/capitol-hill-day

-High/middle school student award for science fair project

https://www.asbmb.org/career-resources/awards-grants-fellowships/science-fair

-Outreach $\$ 500$

https://www.asbmb.org/education/student-chapters/awards/outreach-grant

-Outstanding outreach $\$ 500$

https://www.asbmb.org/education/student-chapters/awards/outstanding-chapter

- Outreach award for $\$ 1,000$

https://www.ascb.org/grants-awards/compass-outreach-grants/

-Public Engagement award \$10,000-\$35,000

-https://www.ascb.org/grants-awards/ascb-public-engagement-grants/

- Travel scholarship $\$ 750$

- Undergraduate Poster Award Competition and Image Contest

https://www.biophysics.org/2022meeting/awards-competitions/travel-awards

-Research Grant \$1,000 for most science fields (\$5,000 for astronomy)

https://www.sigmaxi.org/programs/grants-in-aid

\section{Additional useful resources}

RTK Environmental Group

Melissa StoneBerger Foundation

Connecticut Association of Latinos in Higher Education

Hispanic American Cultural Council
-Scholarship \$1,500 https://rtkenvironmental.com/about/scholarship/

Scholarship

-https://www.melissastonebergerfoundation.org/applying-for-a-scholarship.html

Scholarship $\$ 1,000$

-https://calahe.org/scholarship-eligibility

Scholarship \$2,000 https://hacc-chac.weebly.com/ providing a framework for and a professional community that fosters their success.

Although there exist several organizations that provide opportunities to minority students, several of which are listed above, SACNAS and AISES are the only organizations that have a clear focus on students from URG at not only an institutional level, but also at a chapter development level. While other societies such as ASBMB, the Biophysical Society, and Sigma $\mathrm{Xi}$ have vigorous student chapter programs, these chapters include membership from all demographics and do not have an explicit focus on supporting students from URG. Conversely, organizations such as the ASCB have developed a significant number of programs and activities to support scientists from URG at various career levels but lack student chapter programs.

Chapters organization is specified by each society. For instance, for the societies with primary focus on URG, there are 133 SACNAS chapters classified as student and professional chapters; while AISES chapters are divided into seven regions across the United States and Canada and are further classified into pre-college, college (195), and professional (19) and tribal chapters (3) levels. In general, these organizations provide support to their chapter membership to ensure successful 
development. Common activities designed towards chapter development include examples on how to improve membership recruitment and retention, organize successful community outreach events, professional development activities and fundraising. Moreover, student chapters also constitute a network of other chapters, and frequently the members are eligible to chapter-exclusive opportunities developed by the national organizations.

In addition to these chapter-centered activities, the national organizations continuously adapt their conferences and websites to increase diversity and provide financial support to their membership (Table 1). In this regard, national societies rely on funding from a combination of national, institutional, and local sources, depending on the needs of the society. Major funding for these societies is given from organizations such as the National Institutes of Health (NIH) and the National Science Foundation (NSF), both of which award grants for the recruitment of students, planning of conferences and meetings, mentoring activities and training workshops, and the general promotion of faculty and student diversity in STEM (Table 1). Student chapters of SACNAS, AISES, and ASBMB can apply for funding via grants directly from the national society of which they are a part. However, in some cases, the student chapters may also apply to university student budget committees and student activities committees to fund the chapter, as they would for university-sponsored clubs. Chapters may also seek for external resources by organizing fundraising events, or by establishing partnerships with companies and organizations interested in sponsoring specific events, programs, and potentially awards. These contributions would enable to offer a wide variety of opportunities to their members.

URG student chapters are typically established due to an identified need for a strong network of peers and mentors to provide support for junior minority scientists both locally and nationally. Student chapters often increase their campus presence by collaborating with other student organizations to promote institutional awareness of the need for programs catered to students of URG. Students can also develop outreach programs aimed at K-12 students, allowing members to apply their knowledge while contributing to society by impacting the academic experiences of younger students. Interinstitutional collaboration among chapters also provides students with a larger support system and a broader perspective in their pursuit for professionalism and outreach opportunities. It is for these reasons that minority student chapters are important: they promote the integration and exploration of minorities in professional settings in which they are historically underrepresented.

\section{IMPACT AND RELEVANCE OF PROFESSIONAL SOCIETY STUDENT CHAPTERS ON THE DEVELOPMENT OF UNDERGRADUATE STUDENTS}

Frequently, students become active members of existing chapters or form new chapters because they have undergone challenges and identified needs from previous and current academic experiences. Opinions of undergraduate co-authors of this manuscript highlight the importance of student chapters at universities and colleges and frame the students' rationale for becoming active members of these organizations. Grajales commented that "as a first-generation student, much of the academic qualifications needed to continue my academic career were obscured. Looking back on my experience through high school, I wish I learned of the importance of standardized testing early on and had someone help me write my first resume and fill out financial aid paperwork. I believe these are tasks that minority students often realize late towards the end of their high school years as a result of their parents' lack of experience through the college-application process. Minority students need a mentor who has gone through the application process of college and beyond, teaching them the skills and actions necessary for ongoing growth in an academic and professional setting." Velasquez Baez expressed that "coming from a public-school background, I doubted my abilities to take on a STEM heavy schedule which inherently prevented me from reaching my full potential. I recall the time during my Biology Laboratory course when we were learning how to pipette. It was the first time I had ever placed my hands on any type of lab materials. However, most of the other students in my class had previous experience handling these tools. Although I wanted to learn and master how to properly pipette, I made mistakes during the learning process which lengthened our time completing the lab. Seeing the look of annoyance in my lab partners' faces, I decided to have them lead the lab. This experience made me feel as if I was behind and incompetent of doing basic lab work, hence I did not bother to begin looking for a lab/research opportunity on campus until I felt that I was better prepared." Velasquez Baez also stressed how these disparities make her feel continuously unprepared and that STEM student organizations for minorities have supported her throughout her college career.

The involvement of students that require support, as well as those who have experienced the benefits of organizations and societies, is an essential component of the successful development of chapters. As such, the presence and contributions of students with diverse backgrounds and life experiences are key for providing support to others. In this regard, Grajales commented "my involvement in SACNAS is important to me because it provides me with the opportunity to learn from others. SACNAS provides me with an environment where I am surrounded by like-minded individuals who want to learn from one another to better meet the needs of future generations. I believe that exposure to these diverse and empathetic environments is what allows student chapters to develop effective strategies to help future generations succeed in their journey through academia and beyond". Velasquez Baez expressed a similar sentiment of support and collegiality: "During my time at Wesleyan so far, I have been part of Wesleyan's Math and Science Scholars (WesMaSS) program, the Minority Association of Premedical Students (MAPS), and the SACNAS chapter. All have contributed to helping me advance in my future STEM-related endeavors. In all these organizations I have been able to connect and seek guidance from minority students and professors in order to help me transition from a 
public-school background to a rigorous, STEM heavy schedule at Wesleyan. Participating at these organizations allows me to be part of a community (although small) where we share and learn from each other whether that means tips for studying for certain courses, overcoming imposter syndrome, or research/internship opportunities that are offered on and off campus." Thus, student participation and self-identification with these organizations may play a crucial role in the establishment of successful chapters and the development of supportive resources at an institutional level.

\section{NATIONAL SOCIETIES AND STUDENT CHAPTERS PROMOTING THE DEVELOPMENT OF URG UNDERGRADUATE STUDENTS}

\section{Mentoring}

Research has demonstrated that mentoring relationships are necessary for the academic success of URG students, as constructive feedback results in career success, commitment, and satisfaction in scientists at all stages (Crisp and Cruz, 2009). Engagement of undergraduate students in mentored scientific research experiences is associated with early development of research skills, critical thinking, and scholarly productivity. Experiencing a scientific laboratory environment is known to increase retention in STEM fields (Linn et al., 2015). However, mentoring is not restricted to only the development of scholarly skillsets; social and emotional support is a fundamental consideration while working with undergraduate students, highlighting the importance of competent faculty to advise them. Developing a sense of belonging and building confidence is essential to the successful transition into advanced scientific careers (Chemers et al., 2011; Lopatto, 2007; Thiry and Laursen, 2011). Professional societies provide avenues of support for these activities by offering fellowships and awards for undergraduates to partake in research experiences and present their research at national conferences (Table 1), which ultimately strengthens student interest, motivation, and academic performance (Lopatto, 2007; Russell, 2008; Eagan et al., 2013). For students from URG, mentoring plays a major role in enhanced commitment, resilience, and recruitment into graduate programs and other scientific careers (Nagda et al., 1998; Thiry and Laursen, 2011). Research suggests that minority students perform better when they are mentored by faculty from URG with whom they identify (Campbell and Campbell, 1997; Johnson-Bailey and Cervero, 2004; Blake-Beard et al., 2011). As such, professional societies and associated student chapters with a focus on URG might consider providing additional avenues for matching students with mentors of similar cultural backgrounds to whom they can better connect to maximize the benefits of participation. Thus, it is important that sociocultural diversity is considered when establishing mentoring interactions.

\section{Meetings and Networking Events}

Attending meetings, conferences, and other networking events is an important component of an individual's academic work that is essential when pursuing a career in STEM. These activities allow attendees to present their own research, learn from others in the field, collaborate with other colleagues, expand their networks, and seek potential job opportunities. This is a form of developing a professional identity and recognition in the scientific community, which can encourage young individuals to advance their careers (Womack et al., 2020). In addition, attendees can begin to develop and strengthen interpersonal, networking, and communication skills, all of which are important in academia, among other settings. These events are open to all students and professionals interested in STEM; however, they are predominantly geared towards and attended by graduate students and postdoctoral fellows rather than undergraduate students. A contributing factor is a lack of encouragement for undergraduate students to attend from their professors, as undergraduate educations typically set expectations for students to prioritize completing their degree and securing employment upon graduation, as opposed to promoting rigorous scholarship activities. Unfortunately, these issues are magnified for undergraduate students from URG, and as such, these students are less likely to build those connections and skills early on in their careers, placing them at an inherent disadvantage. To maximize the development of undergraduate students' professional skills, professors should encourage their students to attend these meetings and conferences.

While general meetings directed towards individuals from all backgrounds are beneficial, it is also important to address racial inequity and disparities that exist in the scientific community. For minority students and students from URG, it is often difficult to find the resources and support necessary to achieve future endeavors, especially as they aim for careers in competitive STEM fields (Estrada et al., 2016). Thus, meetings, conferences, and networking events should also be specifically geared towards minority students and actively encourage them to attend. Statistical information available for three of the largest conferences aimed at students from URG is shown in Table 2. In general, demographics show that the attendee population for these conferences is predominantly people from URGs. For instance, since 2016, the demographics of the national SACNAS conference comprised of 87-90\% members belonging to URG and 10-13\% members from non-minority groups (Figure 3; https://www.sacnas.org/what-wedo/conference/). Figure 3 shows the general representation of various racial groups at SACNAS conferences over the past 5 years. For the past few years, the AISES National Conference has reported a consistent conference demographics comprised of $69 \%$ attendees from URG and $31 \%$ non-indigenous attendees, with a majority of college attendees (500-600 students; https://www. aises.org/about/financial-information). It is interesting that the demographic distribution has been consistent through this time, however, an important increase in the number of attendees can be noted for both conferences. Studies suggest that successful retention of diversity in STEM begins with representation, in which professionals from different ethnic and scientific backgrounds hold seats as panelists at meetings and conferences (Estrada et al., 2016; McGee, 2016; Hagan et al., 2020). For students from URG, having the opportunity to be in an interactive environment with successful individuals with whom they 
TABLE 2 | 2020 Statistics for annual conferences focused on URG students in the USA.

\begin{tabular}{|c|c|c|c|c|c|c|}
\hline Conference & Total attendees & Student presenters & $\begin{array}{l}\text { First-time } \\
\text { presenters }\end{array}$ & $\begin{array}{l}\text { FGLI student } \\
\text { presenters }\end{array}$ & $\begin{array}{l}\text { FGLI student } \\
\text { attendees }\end{array}$ & $\begin{array}{l}\text { Exhibiting } \\
\text { institutions }\end{array}$ \\
\hline SACNAS 2020 & $\begin{array}{l}5,767 \text { attendees } \\
27.3 \% \text { Undergraduate; } 14.4 \% \text { Graduate }\end{array}$ & 930 & 742 & 503 & 1981 & 346 \\
\hline AISES 2019 & $\begin{array}{l}1916 \text { attendees } \\
78 \% \text { undergraduate } \\
11 \% \text { Masters } 12 \% \text { Doctorate }\end{array}$ & 518 & $\mathrm{~N} / \mathrm{A}$ & $N / A$ & $\mathrm{~N} / \mathrm{A}$ & 633 \\
\hline ABRCMS 2020 & $\begin{array}{l}3,980+ \\
51.4 \% \text { undergraduate; } 10.5 \% \text { graduate students) }\end{array}$ & 750 & 607 & $N / A$ & $\mathrm{~N} / \mathrm{A}$ & 284 \\
\hline
\end{tabular}

Sources: https://www.sacnas.org/wp-content/uploads/2021/03/SACNAS2020annualreport_FINAL321.pdf; https://www.sacnas.org/wp-content/uploads/2021/05/2020SACNAS_ PostConferenceHighlights3.pdf; https://www.aises.org/about/financial-information; https://www.aises.org/sites/default/files/documents/2018-AlSES-Annual-Report.pdf; https://www. abrcms.org/

FGLI, first-generation low-income.

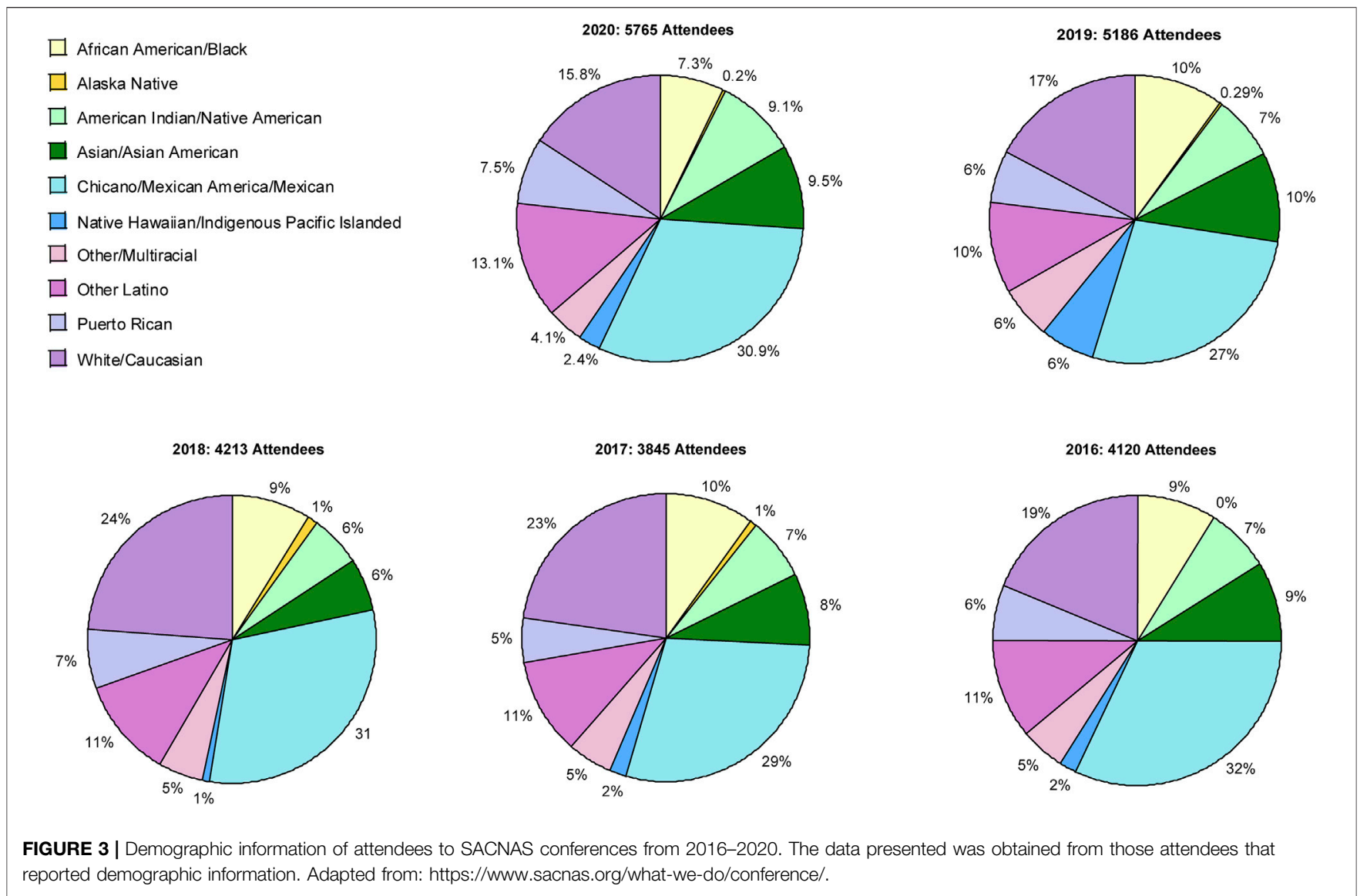

identify fosters a sense of community and belonging. In addition, building a network with peers and professionals can lead to job and funding opportunities as well as the identification of appropriate mentors that understand the needs of the students. As discussed above, a mentor that belongs to a similar URG as the trainee is likely to provide a stronger and more oriented perspective due to a sense of mutual understanding. While there is no specific information available on the statistics and demographics of mentors, judges, and panelists that participate in meetings and conferences, a recent article has discussed the relevance of the demographic composition of mentors and how it should match the demographics of the student attendees. This manuscript also highlighted SACNAS and ABRCMS conferences as having a focus on ensuring diversity in racial and ethnic identities across students, mentors, and board members (Hagan et al., 2020). Thus, representation at STEM conferences and other events can help foster the skills required for the future endeavors of minority students, as opportunities specifically targeted to these individuals contribute to advancing and maintaining diversity in STEM. 
Planning and programming of conferences and meetings specifically designed for undergraduate students from URG may provide solid foundations for these individuals to pursue careers in STEM. Oftentimes, a large number of these undergraduate attendees have never been exposed to a conference environment before, and it is for this reason that providing venues in which these students feel safe and understood is so important. Meetings like SACNAS (Figure 3), AISES and ABRCMS gather an excellent sociocultural combination of professionals and trainees, allowing the community to connect and share common experiences in a way not often found at other meetings. Moreover, programming aimed at undergraduates requires a step back to highlight the big picture of STEM, presenting more general introductions to the various careers available to them as well as resources and steps to attain these careers. Programming including the personal experiences of panelists allows undergraduate students from URG to get a sense of typical career trajectories and help them avoid unnecessary setbacks during their career development. Programming of broader conferences-those open to trainees in general and can also include graduate students or postdoctoral fellows-are typically designed for individuals with a better understanding of STEM careers. In these cases, additional topics, such as explanations of and exposure to future opportunities (e.g., career fairs and job offers), management of interviews, deadlines, and funding resources available, should be considered to make the conferences more accessible to undergraduate students.

\section{Professional Development}

Increasing awareness regarding the insufficient academic preparation and limited opportunities for mentorship and exposure to scientific activities for students from URG has triggered innovative proposals to address the lack of representation in STEM. The recognition of these issues has increased the interest of national organizations to promote professional development during early academic years, with a particular focus on URG. Over the past few years, national organizations like SACNAS, ASBMB, and ASCB have focused on providing undergraduates from URG with professional development training, such as an understanding of and ability to apply skills that are key to future success in STEM careers and higher education environments (Hilty et al., 2019). In addition to targeted conferences and networking and mentoring events, several additional resources have been developed. Webinars offered to undergraduate students have also focused on individual career planning, public health in URG populations, and tools for overcoming discrimination.

Novel career opportunities are available to students. Discussions and panels organized by experts from different fields show the diversity of the STEM job market. Comparisons between careers in academia and careers in industry or policy, among other topics, are now frequent conversations that engage rising undergraduates in emerging scientific fields. While webinars supply information and guidelines for career planning and overcoming barriers in academic environments, seminars, often organized by faculty members, allow student members to gain insights into current research being executed by professionals in STEM fields who come from URG. Frequently, professional organizations provide services to members seeking jobs or internships, such as tips for interviewing and guidelines for building a successful resume. Through the creation of individual institutional chapters led by faculty mentors, undergraduates can also connect with other individuals from URG and work in collaborative atmospheres with their peers to organize events and seminars, as well as consult with faculty mentors. These resources supply undergraduates from URG with opportunities and skills that may not have been available previously due to language, financial, psychological, or other access barriers.

Undergraduates from URG report feeling stress related to the lack of representation in and understanding of their racial and cultural backgrounds by their educational institutions (Hurtado et al., 2002). Societies and chapters provide resources that not only take into account the various backgrounds of the members, but also cater specifically to students who have faced discrimination and struggled with a lack of diversity and inclusivity at their institutions that oftentimes result in limited opportunities available to the minority student population (Allen-Ramdial and Campbell, 2014). However, one issue that remains is that faculty from URG are often expected to assume the task of increasing diversity and inclusion at their respective institutions, regardless of the negative effects this may have on their work or well-being (Mahoney et al., 2008). This burden on faculty can be eased by the practice of cultural competence by non-minority undergraduates as they advance into professional settings. Cultural competence has been defined as a set of congruent behaviors, attitudes, and policies in professional environments, institutions, or agencies that enable effective work in cross-cultural situations (Cross et al., 1989). Cultural competence involves a concerted effort to adjust conventions to benefit the various cultural backgrounds that may not align with one's own. This is an essential practice in professional development for non-minority undergraduates in order to create a wholly welcoming environment for students from URG, both in their current academic settings and as practice for future professional positions. Cultural knowledge, which contributes to cultural competence, can be obtained by exposure to the traditions and perspectives that diverse individuals have as well as societal issues that they face. Webinars and events designed to promote sociocultural competence should not only engage members in efforts centered around their own backgrounds, but also increase interest and knowledge of issues pertaining to certain cultural backgrounds among those who do not personally identify with the webinar topic.

Mentoring opportunities that are designed with student needs in mind, and in which professional development and cultural competence are assessed, increase successful participation in STEM fields (King, 2013). Professional scientists that identify with this mission, such as faculty, chapter leaders and mentors, guest speakers, and webinar interviewees, offer an extended community to undergraduate members from URG. These networks provide the trainees with diverse perspectives, such as personal experiences in STEM, guidelines on how to navigate academia, and expectations for future career endeavors. The 
diversity of opportunities and activities offered by national organizations and local chapters creates a supportive atmosphere for undergraduates from URG through supplying resources and personal and professional guidance, all of which increase self-efficacy. Self-efficacy, or one's confidence and belief in their capacity to succeed in a task or field, can be increased by a supportive environment and by witnessing others from similar backgrounds succeeding in that environment (Mourad et al., 2018).

Webinars and workshops that focus on scientific writing and presentation guidelines provide skills to undergraduates that will further them in their STEM academic and professional paths. Seminars and interviews with professionals from URG in STEM fields allow undergraduates to see individuals from similar backgrounds succeeding in STEM. With these examples, the students may be able visualize a path for themselves in STEM that they had not been able to prior.

Development of leadership skills is also an important component of student participation at institutional chapters. Leadership involves guiding as a group in order to accomplish goals shared by the group as a whole (Northouse, 2013). The process of learning is maximized when an individual fully participates in an activity or process, as opposed to simply watching as others do so (Lave and Wenger, 1991). Therefore, undergraduate chapter members are encouraged to serve on the chapter board. These individuals are involved in decision-making regarding chapter events, community outreach initiatives, fundraising, and involvement in regional and national meetings. Participation of undergraduates as chapter board members allows them to hone leadership skills as they relate to STEM fields and their research. Undergraduates serving on chapter boards fulfill these tenets by making decisions as a unit to accomplish specific goals. In the case of chapters with a focus on diversity and inclusivity in STEM, students seek to help individual members from URG to reach personal and scientific goals and practice professional development and technical skills. However, to fully achieve diversity and inclusion, chapters that serve URG must also consider the participation and views of non-minority students in order to promote institutional equity. Serving on a chapter board provides undergraduates with a way to move from learning through listening and watching as others carry out leadership roles such as leading webinars and seminars, to learning through actively engaging in processes such as planning, decisionmaking, and peer-reviewing as they relate to chapter activities.

A student chapter's organizational structure is typically determined by the size and specific needs of the group. However, in most cases there are necessary officer positions: president, vice president, secretary, and treasurer. The time of election and duration of service of these officers is decided by the students and chapter members. Ideally, these roles will be taken for one or more semesters to allow the student to fully immerse themself in the culture of the chapter, learn the roles associated with the positions, and develop a successful program of activities during the academic year. The typical positions necessary to establish the chapter board represent different kind of responsibilities and require diverse set of skills by the students in charge. For instance, the president is the leader and manager of the student chapter affairs. In general, this individual directs chapter meetings by following a planned agenda, appoints responsibilities, approves any chapter expenses, and represents the chapter publicly as needed. The president may also coordinate work with other institutional or external organizations or delegate this to another board member. The vice president performs the duties of the president when absent or at their request. This officer helps to coordinate meetings and programs and may represent the chapter at institutional or external meetings. The secretary keeps records of chapter activity, helps in advertising events, and is in charge of taking minutes at chapter meetings. The records and participation of the secretary are fundamental to completing annual reports requested by the national organizations. Finally, the treasurer holds the record, reports the chapter income and expenses, and prepares an operating budget when funding is available so that the chapter activities may be planned accordingly.

Student chapters are also spaces in which members can receive feedback on presentations, perform community outreach, engage in social events, and participate in smaller scale regional meetings. Additional resources that national organizations and chapters provide, and which are essential to scientists from URG in training, include support for those seeking jobs or internships during their undergraduate years. An example tailored to students from URG is the "Career Insights" tool on the SACNAS website (https://careercenter.sacnas.org/career-insights/) with which members can view statistics for a particular occupation, such as average annual wage, employment rate, and average education level held by those in that career. Webinars and articles are also offered with tips for successful resume building and interview techniques. These tools can be utilized by undergraduates to begin planning both their academic and professional journeys to maximize the potential of succeeding in a specific career path. Job searching is a process that often requires significant connections within an institution, as well as financial resources to which undergraduates from URG may not have access (Segarra et al., 2020). The availability of webinars, seminars, and mentorship provides resources and prepares undergraduates from URG to succeed in the job market and in internship opportunities. Professional development is a key component of the academic career of any undergraduate student, but especially so for undergraduates from URG, who may not have had access to the resources that allow the practice and maintenance of professional development skills. Thus, through mentorship and leadership programs, meetings, job seeking tools, webinars, and seminars, national organizations and institutional chapters provide an ideal atmosphere for professional development in undergraduates from URG.

\section{NATIONAL SOCIETIES AND URG STUDENT CHAPTERS GIVING BACK: PROMOTING COMMUNITY AND INSTITUTIONAL DEVELOPMENT}

Community development has been broadly defined as "a process where community members come together to take collective action and generate solutions to common problems" 
(UNTERM, 2021). The goal is to achieve sustainable development and provide opportunities to promote equity and social justice. In this regard, student chapters can make a significant impact on the education and empowerment of people outside of their institutions by organizing public activities related to academic training. Similar to the goals proposed within academic institutions, chapters with a focus on URG provide real life examples to members of the community regarding how marginalized people may find an avenue to succeed in STEM professions. Activities are targeted to specific social sectors and planned accordingly to maximize the delivery of the messages. Thus, chapter members must understand and learn how to work with specific groups of individuals. Two of the most common problems encountered by the URG community is implicit bias and imposter syndrome (IS), which pose social and personal challenges. These challenges highlight the importance of URG student chapters in educating the community, as it is likely that several members of these organizations may have been exposed to these problems and therefore possess the necessary background and understanding to help others overcome these issues.

A number of definitions have been used to describe implicit bias. The Kirwan Institute defines it as "attitudes or stereotypes that affect our understanding, actions, and decisions in an unconscious manner. Activated involuntarily, without awareness or intentional control. Can be either positive or negative. Everyone is susceptible" (Staats et al., 2017). Yale's Poorvu Center for Teaching and Learning recognizes implicit bias as the "unconscious attitudes, reactions, stereotypes, and categories that affect the behavior and understanding of various social groups" (Yale Poorvu Center for Teaching and Learning, 2021). Implicit bias has a diverse set of impacts on social interactions in a variety of settings. The implications of implicit bias in academic settings result in assumptions by instructors about students' learning behaviors and their capability for academic success (Yale Poorvu Center for Teaching and Learning, 2021). Studies have shown that such presumptions have a significant negative impact on affected students, oftentimes impeding student growth (Staats et al., 2017). These issues also exist in professional settings in a wide range of environments, such as medical fields, in which the quality and frequency of healthcare services available to minority ethnic groups may be negatively affected (Blair et al., 2011). Given these examples, it is clear that implicit biases can severely limit and even incapacitate the development of individuals from URG in various facets of life. As such, studies have devised methods by which individuals can combat implicit biases, including but not limited to the following (TP Institute, 2021; Yale Poorvu Center for Teaching and Learning, 2021).

- Self-assessment of implicit biases: promotes reflective teaching that offers formal and informal strategies for considering one's own habits. A number of individual tests are available, and instructors can choose to take an online self-assessment to identify their biases (Moon, 2011; TP Institute, 2021).
- Encourage mindfulness: fosters an inclusive environment that supports development of sensitivity and self-awareness.

- Soliciting feedback from external observers: invites individuals to provide honest feedback on your behaviors and how they impact those around you.

Imposter syndrome, also called imposter phenomenon, is loosely defined as feelings of fraudulency and self-doubt (Bridgette et al., 2015). Many individuals who suffer from IS often undermine their own accomplishments, as they believe that they are attributed to external factors such as luck, charm, or network (Bridgette et al., 2015). This feeling is prevalent among high achieving individuals, and even more so among those who undergo significant stress and/or aim for perfection (Bridgette et al., 2015). Studies have shown that IS is highly prevalent in individuals who pursue higher education due to the combination of high expectations and the competition that students undergo in a short period of time (Ramsey and Brown, 2018). For students, stress is a significant factor in IS since it is often difficult to balance academics, personal life, and additional responsibilities (Ramsey and Brown, 2018). In addition, perfection is not a reasonable expectation. When the student is not satisfied with their work, it can lead to a lack of self-confidence and provoke them to work harder and longer in order to achieve something that is not attainable. Intense feelings of IS can be detrimental to the individual's success, as it can lead to burnout, anxiety, and depression (Parkman, 2016), resulting in an increased likelihood for the student to lower their standards and fail to reach their full potential. Therefore, IS often causes students from URG to drop out of school, or even prevent them from pursuing higher education at all, which contributes to the difficulty institutions have in retaining students (Parkman, 2016).

Studies describe a strong prevalence of IS within URG, such as first-generation and ethnic minority students, as they have reported higher levels of stress and depression as well as a lower sense of belonging compared to continuing-students (Bridgette et al., 2015; Le, 2019). First-generation students are individuals who are the first in their family to pursue higher education, whereas continuing-students have family members who have earned at least a bachelor's degree (Redfort and Hoyer, 2017). The differences among the two groups include many barriers that students from URG more commonly face, such as economic instability, decreased family contribution, and lack of cultural support. First-generation students are more likely to come from low-income families and are subsequently highly dependent on grants, scholarships, and employment to afford their education (Postsecondary National Policy Institute, 2021). As such, there is increasing interest within professional societies to support for first-generation, low-income students (Table 2). However, finding, applying, and working for these opportunities takes essential time away from focusing on school and striving for academic excellence. For many graduate schools and programs, students majoring in STEM are expected to have research experience in order to be considered competitive applicants and increase their chances of acceptance (Varsity Tutors an Education Blog, 2021). The average number of hours per week for a research position is $15-20$, but many positions require more 
or less time depending on the field of research. According to the Center for First-Generation Student Success, first-generation students work more hours per week $(20 \mathrm{~h})$ while enrolled in school than their continuing-generation counterparts (12 h). Therefore, the time commitment for a research position is oftentimes unfeasible for first-generation students, especially if it is unpaid or low-wage, on-campus jobs. Therefore, firstgeneration students are more likely to pursue a job off-campus compared to continuing-generation students (Center for Firstgeneration Student Success, 2021). The lack of economic stability is a significant barrier to the future endeavors of many lowincome students who must provide for themselves, especially in comparison to their continuing-generation peers.

First-generation students are less likely to have the resources and emotional support from their families required for success in competitive fields. While emotional support from peers is an important element, colleagues of first-generation students may not understand the hurdles and responsibilities that this group of students has faced. This increases the pressure for students, who must balance family duties with their education. Most parents project expectations on their children based on their own experiences. A parent with an educational background is more likely to have an expectation that their children attend college and secure a reputable career in comparison to a parent who has little to no educational background (Brooks-Terry, 1988). Without a college background, parents of first-generation students may underestimate the rigor of attending college, leaving their children without sufficient emotional support. There may also be an increased sense of guilt in first-generation students, who may feel that they should be prioritizing their family over their education (Brooks-Terry, 1988; Chelsey et al., 2021). Other hurdles may include high levels of stress due to being the first in the family to pursue higher education, and not feeling satisfied with how far they have come despite the barriers they have faced. The lack of emotional support often leaves students discouraged and lowers their expectations, resulting in longer than average times to degree completion. All of these factors contribute to higher levels of stress, depression, and IS.

In many college institutions, especially those that are predominantly white, there are limited resources for firstgeneration and minority students, such as funding and student groups that provide emotional support and representation. Even if these resources are made available to students, first-generation students are less likely to take advantage of on-campus resources, leaving them at higher risk for IS (McGuffey et al., 2019) due to feelings of unworthiness and the fear of not meeting expectations in classes. A plausible preventive measure against these issues would be to address IS at an early age, as this feeling amplifies with time. Hesitancy to take advantage of tutoring services, reach out to professors, or pursue other forms of academic help can lead students to work on assignments for longer than necessary or even underperform. First-generation students are also less likely to take advantage of mental-health services for similar reasons. As an additional contributor, mental health is an unknown subject within the culture of many ethnic groups. Many first-generation students have been told by their families and communities to keep pushing forward and that what they feel is only temporary, which may further deteriorate their mental health in the long run (Aklin and Gómez, 2017; Bailey et al., 2019).

It is evident that economic stability, family contribution, and lack of emotional support are all common barriers among students from URG that increases the risk of IS, placing them at a greater disadvantage in the pursuit of higher education compared to continuing-generation students. Despite these barriers, there are manners in which students and college institutions can prevent IS from significantly impacting academic success. Institutions should prioritize the formation of student groups that promote representation among different ethnic groups, as well as provide emotional and cultural support similar to those which scientific societies tailored to minority students provide. For example, SACNAS and ABRCMS both offer resources to address and help their students overcome IS. SACNAS's "Insights to Success" webinar series (https://www. sacnas.org/what-we-do/webinars/) allowed diverse professionals in STEM fields to share their experiences and the lessons learned facing different challenges in order to move beyond IS, among other personal challenges. Similarly, ABRCMS has a blog in which professionals share their experiences and strategies to overcome these barriers (https://www.abrcms.org/index.php/ education-training/blog). National conferences for these and other scientific societies, as well as workshops and seminars, commonly offer resources with a focus on IS and other relevant personal topics.

Student chapters can also help their membership manage IS. Development of IS workshops that focus on how to self-identify the main features of IS and provide advice and strategies to cope could help combat IS in students. Existing workshops developed by experts in the area typically consist of an initial informational presentation on IS followed by group exercises and discussions that facilitate intimate interactions and allow attendees to overcome or manage this syndrome. Representation should also exist within faculty, as faculty from URG can serve as mentors for underrepresented students and have a positive influence on their sense of belonging and recognition of their own abilities (Ramsey and Brown, 2018). Providing mental health services for all is another way to relieve feelings of IS in students from URG, as addressing mental health can allow students to understand the root causes of IS and manage feelings of selfdoubt and incompetence. Discussions of ways to manage failures are particularly useful, as experiencing failure is a universal experience that everyone will encounter throughout their lifetime (Mind Tools, 2021). Lastly, counseling for time management, studying habits, and other useful skills would also be beneficial for students, and could result in increased confidence and decrease the likelihood of anxiety, depression, and other mental health issues (Wang and Wang, 2018). IS continues to be a prevalent research topic, as it has a significant impact on many lives. Thus, it is important for individuals and institutions to keep up-to-date with data that provide potential resolutions for IS in order to effectively help students in their education and career endeavors.

Overall, students that join institutional chapters seek to assist others in advancing their careers in science and overcoming academic and personal challenges. Chapters with a focus on 
URG intend to foster an inclusive environment for minority students within the institutions. As students from URG embark on their journeys through college, they may feel intimidated by a white-dominated student body. The underrepresentation of people with whom they identify allows for thoughts of doubt to manifest: "do my peers think I am less capable?" or "have other minority students come this far only to drop out and will that be my fate, too?". To combat these intrusive thoughts, student chapters promote social events such as ice cream socials, movie nights, and picnics to provide a safe environment in which students can express themselves and speak openly of their cultures. At these chapters, the students can express their experiences navigating academia in pursuit of professional degrees. In addition to social support, some national organizations and chapters may be able to provide students with economic support, helping to alleviate financial stress and decrease the number of students from URG who forgo the opportunity to attend college due to financial constraints. Some examples of current major funding sources are listed in Table 1. However, these funding sources do not help to alleviate the financial constraints of attending college, but rather create opportunities to strengthen their professional skills and develop a network, among other features.

\section{NATIONAL SOCIETY CHAPTERS AND THEIR IMPACT ON LOCAL COMMUNITIES}

Studies suggest that students lose interest in STEM fields over time (Chung, 2019). Specifically, this low level of interest among older students is characterized by three factors: STEM being perceived as too challenging; a poor perception of scientists and their personal and social lives; and the lack of accessibility to enrichment opportunities (Chung, 2019). In response, scientific and professional national organizations have been developing innovative ideas to eliminate these stigmas that loom over STEM communities. To combat these notions, community-based outreach initiatives have been developed and have proven to be an essential component of STEM education (Chung, 2019). National organizations have attempted to dispel the notion of "nerdiness" so often attributed to STEM students, as young trainees realize that they may soon be in their positions. Community outreach also helps young students realize the various potential STEM avenues of exploration that would otherwise be unknown to them. This assists students in fully understanding the diversity of career options available to STEM professionals, thereby enticing them to further consider STEM careers. In fact, it is vital that outreach programs acknowledge the versatility of job opportunities offered by STEM careers, as young students often neglect the various opportunities encapsulated by it (Chung, 2019). Further fueling students' resistance to considering STEM careers is the blockage of scientific curiosity imposed by physical and financial barriers. Severe inequities in resources impact future generations of college students. Taking this into consideration, it is critical for national organizations to serve as entities that offer educational STEM resources, especially for those communities that lack the funds to provide them for their student bodies. As such, for these national organizations to be most effective, they must target communities that do not already have access to the resources necessary to host early STEM exposure opportunities.

The dissemination of information through college students has proven to make a large impact on how appealing STEM careers appear to young students, as young students are able to identify with the college students. Moreover, college students are often perceived as being more approachable than college faculty, who can appear intimidating to young students. For this reason, efforts to increase the representation of any demographic in STEM must consider community engagement between current college students and younger generations of students.

K-12 students also directly benefit from outreach activities coordinated by student chapters with a focus on URG. Student chapters aim to stimulate curiosity and incentivize exploration of STEM-related fields of study so that students will hopefully engage with the material for reasons beyond academic requirement as they progress in their studies. The encouragement of active participation within student chapters serves to plant the seed of scientific interest in younger generations, enabling them to consider more broadly the various fields encompassed by STEM and begin to develop an idea of what careers they are interested in pursuing. In general, high school outreach programs aim to assist both students preparing for the college application process and those in the midst of it. Offering innovative and state-of-the-art workshops is also important, as these workshops can entice young students and provide advice on how to optimize their time and resources in high school that may contribute to sculpting stellar college applications. Oftentimes, high school students are unaware of the temporal proximity of college applications or of the requirements of their preferred schools. These "blind spots" in high school students can be remedied by enabling interactions between high schoolers from URG and college students from URG, and doing so can set the students up for academic success through sharing personal and academic experiences.

Student members of national organizations that promote academic excellence for students from URG in STEM are largely characterized by their ambition and dedication to making an impact on their communities. These students are able to share their knowledge and experiences in order to enrich themselves and those who follow in their footsteps with respect to navigating their academic and professional careers. Thus, in order to increase the number of students considering careers in STEM, there need to be programs set in place that address the issues outlined above. Taking these factors into consideration, faculty and staff should be participate in seminars that stress the importance of seeking the involvement of college students in leading conversations with younger students regarding STEM, both as a major and as a future career path. By educating the 
general public about issues that hinder the growth of STEM professions, a methodology can be set in place to actively and effectively combat these issues.

\section{COVID-19 PANDEMICS TAUGHT US NEW STRATEGIES. CHAPTERS CONNECTING REMOTELY BRINGS BETTER OPPORTUNITIES}

With the COVID-19 pandemic keeping students isolated from each other, the opportunity to develop meaningful relationships with others has been greatly limited. Under necessary restrictions put in place, it was no longer possible to walk through college campuses and interact with others in in-person classes or study sessions, and most facets of human interaction were relegated to meetings through a computer screen. This transition to a digital social sphere left many first-year students struggling to develop friendships, as most college freshman do. More broadly, shifting educational programs and conferences to an online setting created a steep learning curve for most. This led to suboptimal communication processes, oftentimes resulting in the loss of audience attention. All in all, the pandemic paused all sorts of traditional social interaction.

Despite the lack of normalcy, the COVID-19 pandemic pushed standing institutions into adopting new forms of communication. Although the adjustment to these new standards was difficult, it was because of the pandemic that educational programs diversified the means by which they distribute information. In many situations, this transition to a more digitized world increased the feasibility and timeliness of social interactions. For example, having meetings online forced students to adopt a strict itinerary, allowing them to better organize themselves in their day-to-days. This transition also benefitted some studenttutor interactions, as students no longer needed to leave the comfort of their dorms and homes to receive support from professors. This shift also provided faculty with a wealth of student resources, as the eligibility to serve as a tutor was no longer limited to students in the immediate area of the educational community. Significantly, many of the changes that arose in the wake of COVID-19 onset appear to be in the process of becoming permanently adopted techniques. While perhaps the most notable change is the revitalized need for upholding high standards of hygiene in all social spaces, the newly established residence of digitized professional social interactions has also made a great impact. For many, remote meetings are not only a fleeting phenomenon, but a standard by which to organize professional communication in the future. However, despite current efforts to make STEM available under these challenging conditions, students from URG may be at a disadvantage compared to their non-minority peers. Students from URG may lack access to computers, internet, or technological tools used in remote meetings. Thus, personal challenges again may affect how these individuals engage with the virtual world. It is important for institutions to ensure that all students, regardless of racial background, have access to this technology at home.

The COVID-19 outbreak revitalized attention to research and health; however, disparities in the latter increased over the pandemic. The CDC commented on this issue, highlighting that social and racial injustice has "unequally affected many racial and ethnic minority groups, putting them at more risk of getting sick and dying from health complications" (Centers for Disease Control and Prevention, 2021). It will be interesting to see the development of young trainees from URG as a community effort to eliminate these social injustices.

\section{FUTURE DIRECTIONS: HOW NATIONAL SOCIETIES AND CHAPTERS ARE ADAPTING TO CHANGE AND PROBLEMS}

The COVID-19 pandemic has been a lesson for national societies in problem solving and streamlining programs and events in order to most effectively allow communication and learning among undergraduates from URG. The transition of many annual conferences from in-person to virtual seminars and research presentations bodes well for the overcoming of challenges that national societies may encounter in the future. Over the past year, student chapters have had to surmount the limits on their ability to meet in person and host activities and events that foster a continued sense of community within their institutional chapters. Exposure of the work that national societies and chapters perform to the public will not only increase awareness of the need for inclusivity and diversity in STEM, but also strengthens community, institutional, and national support via funding and donations.

\section{CONCLUSION}

The ability to bring together students of diverse backgrounds but with common experiences in their STEM education journey results in the formation of communities both within individual institutions and nationally, as well as building personal, academic, and professional confidence. National societies and institutional student chapters with a focus on diversity and inclusion in STEM are fundamental players in the development of this network. They not only promote the development of essential skillsets in students from URG, but also foster public interest in STEM and provide early STEM education for K-12 students. Equally as important is the diversity of the faculty that lead these conversations with the students, as students are more likely to believe in and follow advice given from with a person with whom they identify. Increasing the diversity of these educators also maximizes the opportunity for student engagement, as educators of different backgrounds appeal to students of different demographics. Promoting diversity of educators helps students from URG to not only overcome challenges related to STEM engagement, but also overcome personal challenges, such as imposter syndrome and implicit biases. As such, the impact of national societies and student chapters transcends that of educational information services and extends into the motivation and inspiration for younger trainees. 
Efforts and opportunities for students from URG provided by these organizations should be focused on helping these students navigate domains that may otherwise have appeared too daunting or beyond their reach.

\section{AUTHOR CONTRIBUTIONS}

$\mathrm{DH}$ and TP-B conceived of and designed the research; LB, JG, and JVB compiled and analysed data; LB and JG prepared figures and tables; LB, JG, JVB, and TP-B drafted the manuscript; all authors edited and revised the manuscript; all authors approved the final version of the manuscript.

\section{REFERENCES}

Aklin, F., and Gómez, M. M. (2017). Minorities and Mental Health: Moving beyond Stigma. Bethesda, MD: NIMHS Insights.

Allen-Ramdial, S. A., and Campbell, A. G. (2014). Reimagining the Pipeline: Advancing STEM Diversity, Persistence, and Success. Bioscience 64, 612-618. doi:10.1093/biosci/biu076

Bailey, R. K., Mokonogho, J., and Kumar, A. (2019). Racial and Ethnic Differences in Depression: Current Perspectives. Neuropsychiatr. Dis. Treat. 15, 603-609. doi:10.2147/NDT.S128584

Blair, I. V., Steiner, J. F., and Havranek, E. P. (2011). Unconscious (Implicit) Bias and Health Disparities: where Do We Go from Here? Perm J. 15, 71-78.

Blake-Beard, S., Bayne, M. L., Crosby, F. J., and Muller, C. B. (2011). Matching by Race and Gender in Mentoring Relationships: Keeping Our Eyes on the Prize. J. Soc. Issues 67. doi:10.1111/j.1540-4560.2011.01717.x

Branchaw, J., Guerrero, L., and Pfund, C. (2020). Interventions to Optimize Mentoring Relationships for Diverse Biomedical Researchers. Understanding Interventions 11. https:/www.understandinginterventionsjournal.org/article/ 12479-interventions-to-optimize-mentoring-relationships-for-diverse-biomedicalresearchers.

Bridgette, L. M., Peteet, J., and Weekes, J. C. (2015). Predictors of Imposter Phenomenon Among Talented Ethnic Minority Undergraduate Students. J. Negro Educ. 84, 175-186. https://eric.ed.gov/?id=EJ1216343. ISSN: ISSN0022-2984.

Brooks-Terry, M. (1988). Tracing the Disadvantages of First-Generation College Students: An Application of Sussman's Option Sequence Model. Boston, MA.

Campbell, T. A., and Campbell, D. E. (1997). Faculty/Student Mentor Program: Effects on Academic Performance and Retention. Res. Higher Educ. 38, 727-742. doi:10.1023/a:1024911904627

Centers for Disease Control and Prevention (2021). Health Equity Considerations and Racial and Ethnic Minority Groups. https://www.cdc.gov/coronavirus/ 2019-ncov/community/health-equity/race-ethnicity.html.

Center for First-generation Student Success (2021). First-generation College Students' Employment. NASPA. https://firstgen.naspa.org/files/dmfile/ FactSheet-04.pdf.

Chemers, M., Zurbriggen, E., Syed, M., Goza, B., and Bearman, S. (2011). The Role of Efficacy and Identity in Science Career Commitment Among Underrepresented Minority Students. J. Soc. Issues 67, 469. doi:10.1111/ j.1540-4560.2011.01710.x

Chung, D. (2019). Cultivating Scientific Curiosity Starts Early: The Importance of STEM Outreach Initiatives for K-12, IMMpress Magazine. Toronto, Canada: The Magazine for the University of Toronto Department of Immunology.

Crisp, G., and Cruz, I. (2009). Mentoring College Students: A Critical Review of the Literature between 1990 and 2007. Res. High Educ. 50, 525-545. doi:10.1007/ s11162-009-9130-2

Cross, T., Bazron, B., Dennis, K., and Isaacs, M. (1989). Towards a Culturally Competent System of Care. Washington, DC: Georgetown University Child Development Center, CASSP Technical Assistance Center, 1.

\section{FUNDING}

LB received the 2021 Undergraduate Research Award from ASBMB during the period that this manuscript was developed. DH is supported by NIH grant R25GM113686. TP-B. is supported by NIH grant R01AR077578.

\section{ACKNOWLEDGMENTS}

The authors are thankful to Dr. Cat McCann and Dr. Monserrat Olea-Flores for their critical comments on this manuscript.

Eagan, M. K., Hurtado, S., Chang, M. J., Garcia, G. A., Herrera, F. A., and Garibay, J. C. (2013). Making a Difference in Science Education: The Impact of Undergraduate Research Programs. Am. Educ. Res. J. 50, 683-713. doi:10.3102/0002831213482038

Estrada, M., Burnett, M., Campbell, A. G., Campbell, P. B., Denetclaw, W. F., Gutiérrez, C. G., et al. (2016). Improving Underrepresented Minority Student Persistence in STEM. CBE Life Sci. Educ. 15. doi:10.1187/cbe.16-01-0038

Hagan, A. K., Pollet, R. M., and Libertucci, J. (2020). Suggestions for Improving Invited Speaker Diversity to Reflect Trainee Diversity. J. Microbiol. Biol. Educ. 21. doi:10.1128/jmbe.v21i1.2105

Hilty, D. M., Liu, H. Y., Stubbe, D., and Teshima, J. (2019). Defining Professional Development in Medicine, Psychiatry, and Allied Fields. Psychiatr. Clin. North. Am. 42, 337-356. doi:10.1016/j.psc.2019.04.001

Holden, C. L., Wright, L. E., Herring, A. M., and Sims, P. L. (2021). Imposter Syndrome Among First- and Continuing-Generation College Students: The Roles of Perfectionism and Stress. J. Coll. Student Retention. doi:10.1177/ 15210251211019379

Hurtado, S., Faye Carter, D., and Kardia, D. (2002). The Climate for Diversity: Key Issues for Institutional Self-Study. New Dir. Institution. Res. 1998, 53. doi:10.1002/ir.9804

Johnson-Bailey, J., and Cervero, R. M. (2004). Mentoring in Black and white: the Intricacies of Cross-Cultural Mentoring. Mentor. Tutor. Partnersh. Learn. 12, 7-21. doi:10.1080/1361126042000183075

King, L. (2013). Helping Early Career Research Scientists Ascend the Professional Ladder. Trends Biochem. Sci. 38, 373-375. doi:10.1016/j.tibs.2013.06.001

Lave, J., and Wenger, E. (1991). "Learning in Doing: Social, Cognitive and Computational Perspectives". In Situated Learning: Legitimate Peripheral Participation. Cambridge: Cambridge University Press.

Le, L. (2019). Unpacking the Imposter Syndrome and Mental Health as a Person of Color First Generation College Student within Institutions of of Color First Generation College Student within Institutions of Higher Education. Higher Educ. McNair Res. J. SJSU 15. https://scholarworks.sjsu.edu/mcnair/vol15/ iss $1 / 5$.

Linn, M. C., Palmer, E., Baranger, A., Gerard, E., and Stone, E. (2015). Education. Undergraduate Research Experiences: Impacts and Opportunities. Science 347, 1261757. doi:10.1126/science. 1261757

Lopatto, D. (2007). Undergraduate Research Experiences Support Science Career Decisions and Active Learning. CBE Life Sci. Educ. 6, 297-306. doi:10.1187/ cbe.07-06-0039

Mahoney, M. R., Wilson, E., Odom, K. L., Flowers, L., and Adler, S. R. (2008). Minority Faculty Voices on Diversity in Academic Medicine: Perspectives from One School. Acad. Med. 83, 781-786. doi:10.1097/ACM.0b013e31817ec002

McGee, R. (2016). "Biomedical Workforce Diversity: The Context for Mentoring to Develop Talents and Foster Success within the 'Pipeline'". AIDS Behav. 20 (Suppl. 2), 231-237. doi:10.1007/s10461-016-1486-7

Mind Tools (2021). "Overcoming Fear of Failure," in Facing Your Fear of Moving Forward. Westminster, London. https://www.mindtools.com/pages/article/ fear-of-failure.htm.

Moon, T. R. (2011). Project Implicit. Charlottesville, VA. https://implicit.harvard. edu/implicit/takeatest.html. 
Mourad, T. M., McNulty, A. F., Liwosz, D., Tice, K., Abbott, F., Williams, G. C., et al. (2018). The Role of a Professional Society in Broadening Participation in Science: A National Model for Increasing Persistence. BioScience 68, 715-721. doi:10.1093/biosci/biy066

Nagda, B. A., Gregerman, S. R., Jonides, J., von Hippel, W., and Lerner, J. S. (1998). Undergraduate Student-Faculty Research Partnerships Affect Studen Retention. Rev. Higher Educ. 22, 55-72. doi:10.1353/rhe.1998.0016

Northouse, P. G. (2013). Leadership: Theory and Practice. Thousand Oaks, CA: Sage Publications Inc.

Parkman, A. (2016). The Imposter Phenomenon in Higher Education: Incidence and Impact. J. Higher Educ. Theor. Pract. 16. http://www.na-businesspress.com/ JHETP/ParkmanA_Web16_1_.pdf.

Postsecondary National Policy Institute (2021). First-generation Students in Higher Education. Postsecondary National Policy Institute (PNPI). https:// pnpi.org/wp-content/uploads/2020/11/FirstGenStudentsinHigherEd_ November2020-FINAL-1.pdf.

Ramsey, E., and Brown, D. (2018). Feeling like a Fraud: Helping Students Renegotiate Their Academic Identities. Coll. Undergraduate Libraries 25, 86-90. doi:10.1080/10691316.2017.1364080

Redfort, J., and Hoyer, K. M. (2017). "First-Generation and Continuing-Generation College Students: A Comparison of High School and Postsecondary Experiences," in Stats in Brief (Washington, DC: U.S. Department of Education).

Russell, S. H. (2008). "Undergraduate Research Opportunities: Facilitating and Encouraging the Transition from Student to Scientist," in Creating Effective Undergraduate Research Programs in Science (Washington, DC: Teachers College Press), 53-80.

Segarra, V. A., Vega, L. R., Primus, C., Etson, C., Guillory, A. N., Edwards, A., et al. (2020). Scientific Societies Fostering Inclusive Scientific Environments through Travel Awards: Current Practices and Recommendations. CBE Life Sci. Educ. 19, es3. doi:10.1187/cbe.19-11-0262

Staats, C., Capatosto, K., Tenney, L., and Mamo, S. (2017). State of the Science: Implicit Bias Review. Columbus, Ohio: Kirwan Institute for the Study of Race and Ethnicity.

Thiry, H., and Laursen, S. L. (2011). The Role of Student-Advisor Interactions in Apprenticing Undergraduate Researchers into a Scientific Community of Practice. J. Sci. Educ. Technol. 20, 771-784. doi:10.1007/s10956-010-9271-2

TP Institute (2021). "Implicit Bias," in Research: Science \& Perception. Washington, DC.
McGuffey, A., George, L., and Duraj, J. (2019). First-Generation Students: Retention and Intervention. University Business. https://universitybusiness.com/firstgeneration-students-retention-and-intervention/.

UNTERM (2021). Community Development. Available at: https://web.archive. org/web/20140714225617/http://unterm.un.org/DGAACS/unterm.nsf/ 8fa942046ff7601c85256983007ca4d8/526c2eaba978f007852569fd00036819? OpenDocument (Accessed August 3, 2021).

Varsity Tutors an Education Blog (2021). Why Research Experience Is Important for Grad School Apps. Editor V Tutors. https://www.varsitytutors.com/blog.

Vernon, T. M. W., and Morris, R. (2017). The Role of Professional Societies in STEM Diversity. J. Natl. Tech. Assoc. 87, 22-31.

Wang, P., and Wang, X. (2018). Effect of Time Management Training on Anxiety, Depression, and Sleep Quality. Iran J. Public Health 47, 1822-1831. https:// www.ncbi.nlm.nih.gov/pmc/articles/PMC6379615/.

Womack, V. Y., Thakore, B. K., Wood, C. V., Jewett, D. C., Jones, R. F., Ingram, S. L., et al. (2020). The ASPET Mentoring Network: Enhancing Diversity and Inclusion through Career Coaching Groups within a Scientific Society. CBE Life Sci. Educ. 19, ar29. doi:10.1187/cbe.19-10-0195

Yale Poorvu Center for Teaching and Learning (2021). Awareness of Implicit Biases. Yale University. https://poorvucenter.yale.edu/ImplicitBiasAwareness.

Conflict of Interest: The authors declare that the research was conducted in the absence of any commercial or financial relationships that could be construed as a potential conflict of interest.

Publisher's Note: All claims expressed in this article are solely those of the authors and do not necessarily represent those of their affiliated organizations, or those of the publisher, the editors and the reviewers. Any product that may be evaluated in this article, or claim that may be made by its manufacturer, is not guaranteed or endorsed by the publisher.

Copyright (C) 2021 Barnes, Grajales, Velasquez Baez, Hidalgo and Padilla-Benavides. This is an open-access article distributed under the terms of the Creative Commons Attribution License (CC BY). The use, distribution or reproduction in other forums is permitted, provided the original author(s) and the copyright owner(s) are credited and that the original publication in this journal is cited, in accordance with accepted academic practice. No use, distribution or reproduction is permitted which does not comply with these terms. 